\title{
Microstructural and Fractographic Characterization of a Thermally Embrittled Nuclear Grade Steel: Part II - Quenching and Tempering
}

\author{
José R. Tarpani*, Maria H.P. Braz, Waldek W. Bose Filho and Dirceu Spinelli \\ Engineering School of São Carlos, University of São Paulo \\ Av. Trabalhador São-Carlense 400, 13566-590 São Carlos-SP, Brazil
}

Received: September 27, 2001; Revised: July 10-, 2002

\begin{abstract}
A nuclear reactor pressure vessel steel was submitted to different quenching and tempering heat treatments aimed at simulating neutron irradiation damage. The obtained microstructures were mechanically tested and submitted to metallographic and fractographic survey. The relevant microstructural and fractographic aspects were employed in the interpretation of the mechanical performance of the thermally embrittled microstructures. A well defined correlation was determined between the elastic-plastic fracture toughness parameter J-integral and the Charpy impact energy, which was achieved for some of the Q\&T microstructures.
\end{abstract}

Keywords: fractography, fracture toughness, microstructure, pressure vessel steel

\section{Introduction}

In Part I of this study ${ }^{1}$, a nuclear grade steel was annealed under several soaking times and temperatures, rendering to it a broad spectrum of elastic-plastic fracture toughness in both quasi-static (J-R curve) and dynamic (Charpy impact) loading regimes. In that occasion, the feasibility of simulating the fracture toughness behavior of neutron damaged structural steels was then verified. Also, it was demonstrated that the embrittling mechanism of the nuclear grade low alloy steel was mainly due to grain growth, so a Hall-Petch type relationship was then suggested. However, it was observed that a typical characteristic of irradiated steels, viz. a sharp increase in both the hardness and the tensile mechanical properties, could not be adequately simulated by ordinary annealing heat treatments. For instance, while the original steel exhibited a Rockwell hardness $\left(\mathrm{R}_{\mathrm{B}}\right)$ of 88 , its annealing microstructures fell on the range 86-95 $R_{B}$, therefore fair close to the hardness of the steel in the as-received condition. The same pattern was verified in both yield and ultimate tensile strengths. Hence, the option was made by the acquisition of quenched and tempered (Q\&T) microstructures that could satisfy both requirements of embrittlement and hardening of the steel, thus simulating more properly the as- irradiated condition. These complementary results are presented here.

\section{Material}

The Brazilian ASTM A508-3A steel, typically used to fabricate PWR vessels for the nuclear industry, has been fully characterized in Part $\mathrm{I}^{1}$.

\section{Experimental}

\section{Heat Treatment}

The Q\&T thermal cycles applied to the A508-3A steel in the as-received condition, here denominated of $\boldsymbol{A}$, are illustrated in Fig. 1.

\section{Quasi-static and Dynamic Fracture Toughness}

The same procedures applied for the annealed microstructures ${ }^{1}$ to determine their J-R curves and impact Charpy energies at $300{ }^{\circ} \mathrm{C}$, were adopted here.

\section{Metalography and Fractography}

The metalographic and fractographic characterization of the Q\&T resulting microstructures was performed using an automated image analyzer and a scanning electron microscope equipped with a microprobe, respectively.

*e-mail: jrpan@sc.usp.br 

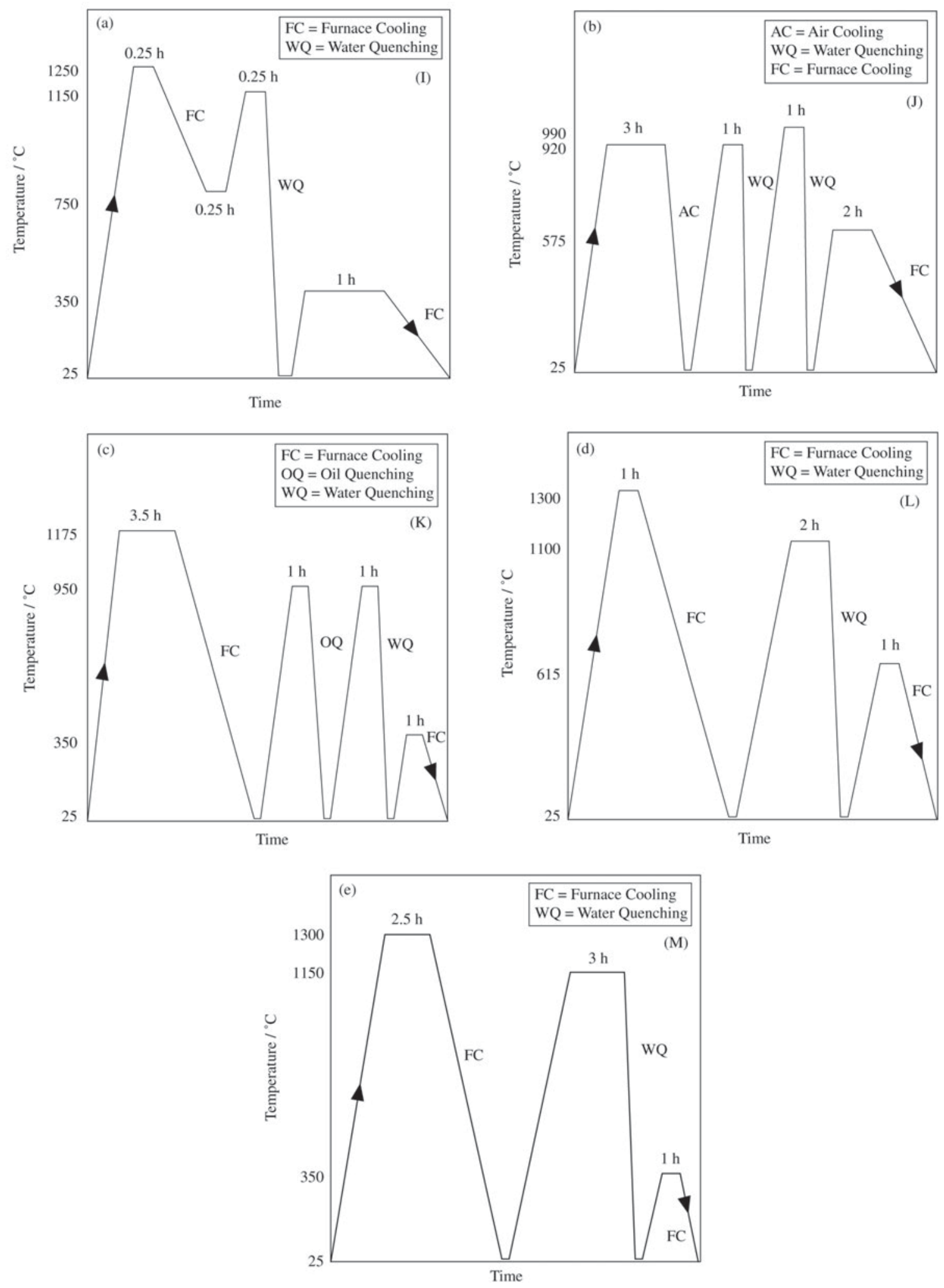

Figure 1. Thermal cycles of the Q\&T heat treatments individually applied to the A508 steel in the as-received condition: a) $\boldsymbol{I}$, b) $\boldsymbol{J}$; c) $\boldsymbol{K}$, d) $\boldsymbol{L}$ and e) $\boldsymbol{M}$. 


\section{Results}

\section{Metallography}

It can be seen in Fig. 2a, that the microstructure $\boldsymbol{I}$ is composed of low carbon martensite, slightly decomposed in ferrite and carbides during the $350{ }^{\circ} \mathrm{C}$ tempering treatment. The largest austenite grain size obtained among all the tested microstructures, increased the steel hardenability and so favored both martensite transformation (at the expenses of the bainite) and austenite retaining, the latter as small acicular areas in Fig. 2a. Partial recrystallization, occurring during discontinuous cooling, induced a heterogeneous distribution of austenitic grains, and consequently, created a gradient in the mechanical properties. The elevated austenitizing temperatures favored the formation of a coarse microstructure, as well as alloying segregation at the grain boundaries. This segregation caused the intergranular fracture mode observed during quasi-static fracture toughness testing. The microstructure $\boldsymbol{J}$, Fig. $2 \mathrm{~b}$, presents heavily spheroidized carbides as a result of the tempering treatment at $575{ }^{\circ} \mathrm{C}$. The material's hardenability was reduced due to the recrystallization, grain homogenization and refinement cycles, sequentially applied to the material ${ }^{2-4}$, which prevented austenite retaining and favored the formation of tempered bainite, at the expenses of the martensite. The microstructure $\boldsymbol{K}$, Fig. 2c, exhibits a quite complex arrangement of different phases, in which it can be inferred retained
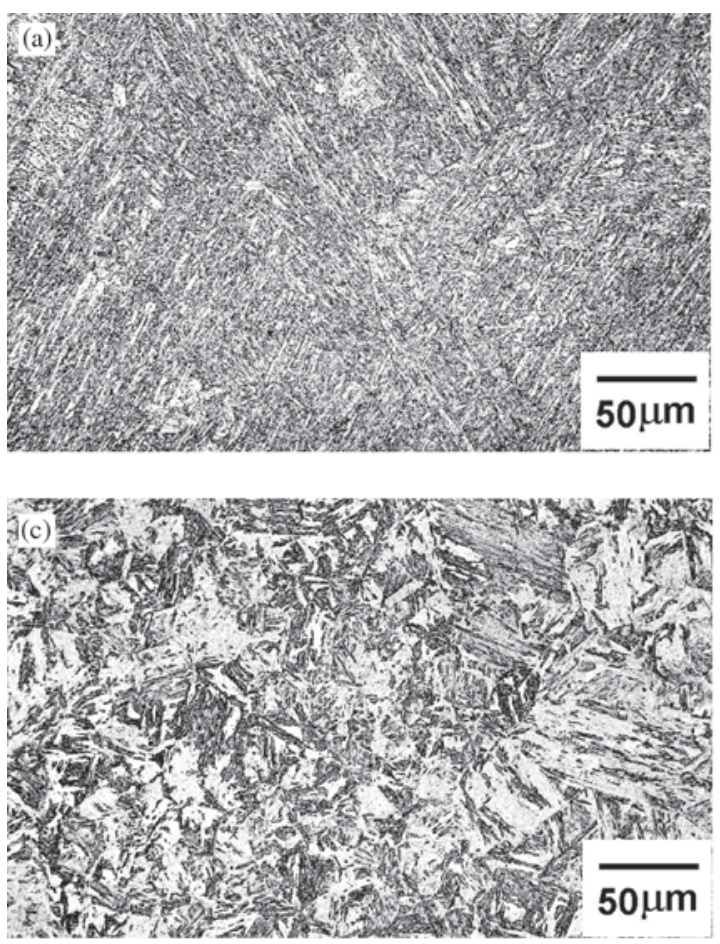
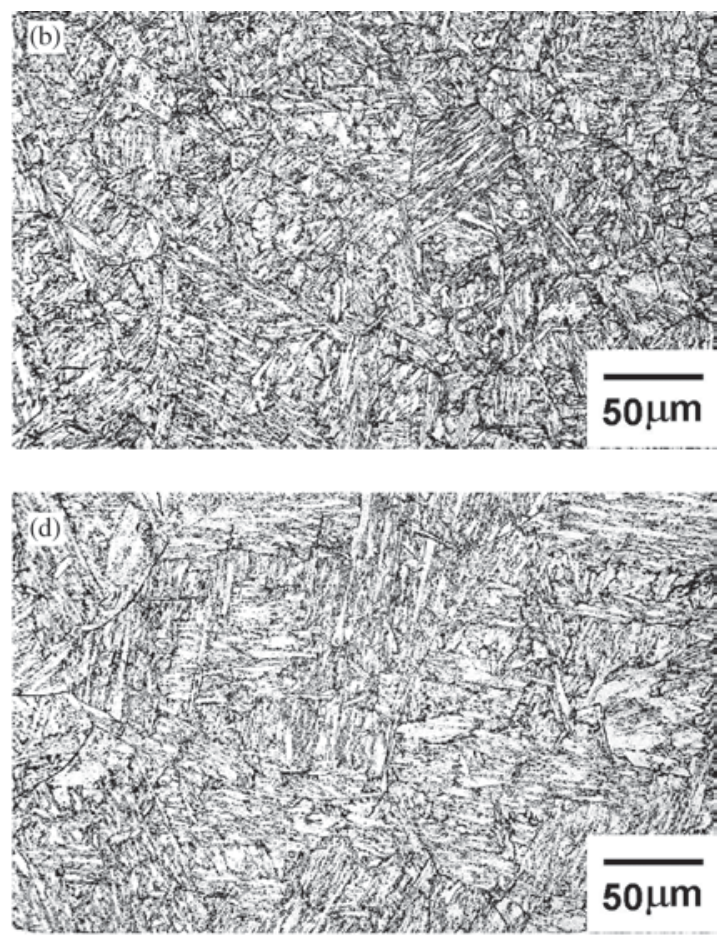

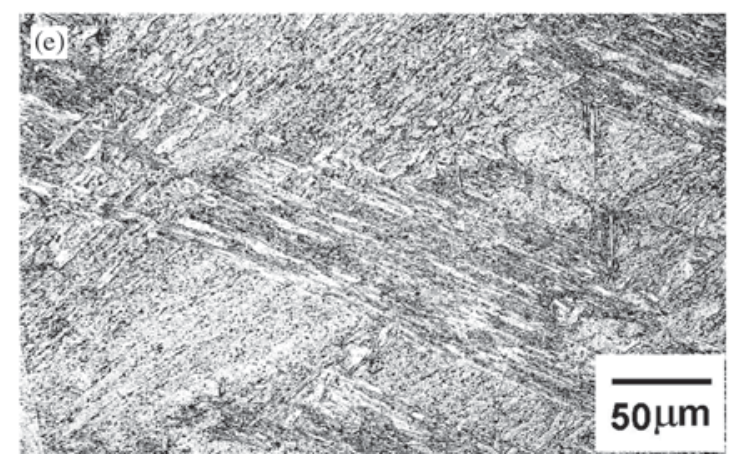

Figure 2. Microstructures obtained from quenching and tempering (Q\&T) the A508 steel: a) $\boldsymbol{I}$, b) $\boldsymbol{J}$; c) $\boldsymbol{K}$, d) $\boldsymbol{L}$ and e) $\boldsymbol{M}$. Etched in Nital $2 \%$. 
austenite, martensite, bainite and a mixture of ferrite and carbides slightly coalesced during the $350{ }^{\circ} \mathrm{C}$ tempering process. The microstructure $\boldsymbol{L}$, Fig. 2 d, maintain great morphologic similarity to the microstructure $\boldsymbol{J}$, probably due to the likeness between their quenching and final tempering conditions. However, as a consequence of higher austenitizing soaking time and temperature applied to $\boldsymbol{L}$, comparatively to $\boldsymbol{J}$, as well as the absence of grain refinement and homogenization steps in the former, it rendered to $\boldsymbol{L}$ a coarser microstructure. This leads to a lower toughness value to $\boldsymbol{L}$ when compared to $\boldsymbol{J}$, as later verified in the mechanical tests. The microstructure $\boldsymbol{M}$, Fig. 2e, resembles microstructure $\boldsymbol{I}$ related to grain coarseness, as a result of very high austenitizing soaking times and temperatures. This condition also induced segregation at grain boundaries and intergranular crack propagation in the quasi-static J-fracture toughness specimens. Likewise microstructure $\boldsymbol{I}$, the very high hardenability caused by large austenitic grain size in $\boldsymbol{M}$, gave rise to low carbon martensite, instead of bainite.

Table I provides the bainitic/martensitic packet sizes, for microstructures $\boldsymbol{I}-\boldsymbol{M}$. So far, the qualitative and quantitative microstructural characterization of these Q\&T microstructures have not been fully accomplished, and therefore are only partially presented in this study. Anyway, except for the $\boldsymbol{K}$ microstructure, all the others could be classified as monophasic microstructures, with $\boldsymbol{I}$ and $\boldsymbol{M}$ exhibiting martensite and $\boldsymbol{J}$ and $\boldsymbol{L}$, bainite, as predominant phases.

The Rockwell hardness of the steel under Q\&T conditions ranged from 23.5 to $38.8 \mathrm{R}_{\mathrm{C}}$, thence significantly higher than that found for the material in the as-received condition $\left(88 \mathrm{R}_{\mathrm{B}}\right)$. Also, the yield and the ultimate tensile strengths obtained in the tensile tests for the Q\&T conditions were substantially higher than those determined for the A508 steel in the as-delivered condition. So, as opposed to the annealed microstructures ${ }^{1}$, the Q\&T microstructures successfully simulate the hardening effect typically developed in nuclear grade steels in the irradiated condition. The so-desired embrittlement of the A508 steel through Q\&T heat treat-

Table I. Grain diameters for the A508 steel in its original, $\boldsymbol{A}$, and Q\&T conditions, $\boldsymbol{I}-\boldsymbol{M}$. The ASTM micrograin size is provided in brackets.

\begin{tabular}{cc}
\hline $\begin{array}{c}\text { Quenching and Tempering } \\
\text { Heat Treatment }\end{array}$ & $\begin{array}{c}\mathrm{D}_{\text {bainite/martensite }} \\
(\mu \mathrm{m})\end{array}$ \\
\hline $\boldsymbol{A}$ & $19(8.5)$ \\
$\boldsymbol{I}$ & $775(00)$ \\
$\boldsymbol{J}$ & $105(3.5)$ \\
$\boldsymbol{K}$ & $119(3.2)$ \\
$\boldsymbol{L}$ & $153(2.5)$ \\
$\boldsymbol{M}$ & $589(00)$ \\
\hline
\end{tabular}

ments was confirmed by means of fractographic analysis and fracture mechanics concepts, as discussed bellow.

\section{Fractography}

As seen in Fig. 3, the fractographic characteristics of the Q\&T microstructures, when submitted to a quasi-static loading condition (J-R curve), are substantially different from the annealed materials, as previously shown in Part I. The microstructures $\boldsymbol{I}$ and $\boldsymbol{M}$ exhibit a quite distinguishable intergranular fracture mode, Figs. $3 \mathrm{a}$ and $3 \mathrm{e}$, and it was due to the $\mathrm{C}$ and $\mathrm{Mn}$ segregation at the grain boundaries, as discovered by chemical microanalysis. The grain size found in microstructure $\boldsymbol{I}$ is markedly larger than that of microstructure $\boldsymbol{M}$, as an indicative of the temperature predominance over the austenitizing time on the grain growth kinetics. The microstructures $\boldsymbol{J}$ and $\boldsymbol{L}$, Figs. $3 \mathrm{~b}$ and $3 \mathrm{~d}$, are characterized by a wide distribution of microvoids, resembling microstructure $\boldsymbol{A}^{1}$. The microstructure $\boldsymbol{L}$ exhibits a more planar fracture aspect, or less energetic than $\boldsymbol{J}$. This was later confirmed by the respective values of the fracture toughness parameter $\mathrm{dJ} / \mathrm{d} \Delta a_{(1 \mathrm{~mm})}{ }^{1}$. In fact, amongst all the Q\&T microstructures, only $\boldsymbol{J}$ and $\boldsymbol{L}$ were adequately devised for the simulation of the elastic-plastic mechanical behavior of neutron damaged steels. The microstructure $\boldsymbol{K}$, Fig. 3c, presented an incipient ductile and stable crack propagation before the specimen fail in a brittle and catastrophic fracture mode. The stable portion of the crack propagation shows large areas of quasi-cleavage fracture mode, surrounded by predominant regions of nucleation, growth and coalescence of microvoids. It can be concluded that the $\mathrm{dJ} / \mathrm{d} \Delta a_{(1 \mathrm{~mm})}$ parameter keeps its physical meaning of ductile cracking only for the microstructures $\boldsymbol{J}$ and $\boldsymbol{L}$.

In regard to the fracture behavior under impact load, Figs. $4 \mathrm{~b}$ and $4 \mathrm{~d}$ show that the $\boldsymbol{J}$ and specially the microstructure $\boldsymbol{L}$, exhibit some sparce quasi-cleavage regions, denoting the effect of the strain rate on microstructural embrittlement. The fracture aspects of these two microstructures faithfully reflect the absorbed energy values under impact conditions at $300{ }^{\circ} \mathrm{C}$, when the microstructure $\boldsymbol{J}$ exhibited a J-fracture toughness slightly superior to that obtained for $\boldsymbol{L}$. A quite interesting and unexpected fact was observed in the fracture behavior under dynamic loading of microstructures $\boldsymbol{I}, \boldsymbol{K}$ e $\boldsymbol{M}$, Figs. 4a, 4c and 4e, respectively. Even though they presented intergranular fracture mode or brittle fracture after some incipient ductile growth in the quasi-static loading condition, i.e. J-R curve testing, under impact loading a typical ductile fracture surface aspect was developed, with massive presence of microvoids oriented in the direction of crack growth. This occurrence discloses the extreme sensitivity of these microstructures to the imposed strain rate during the fracture toughness test. Nevertheless, it should be emphasized that this sensitivity was expressed in a reverse fashion than that normally observed 

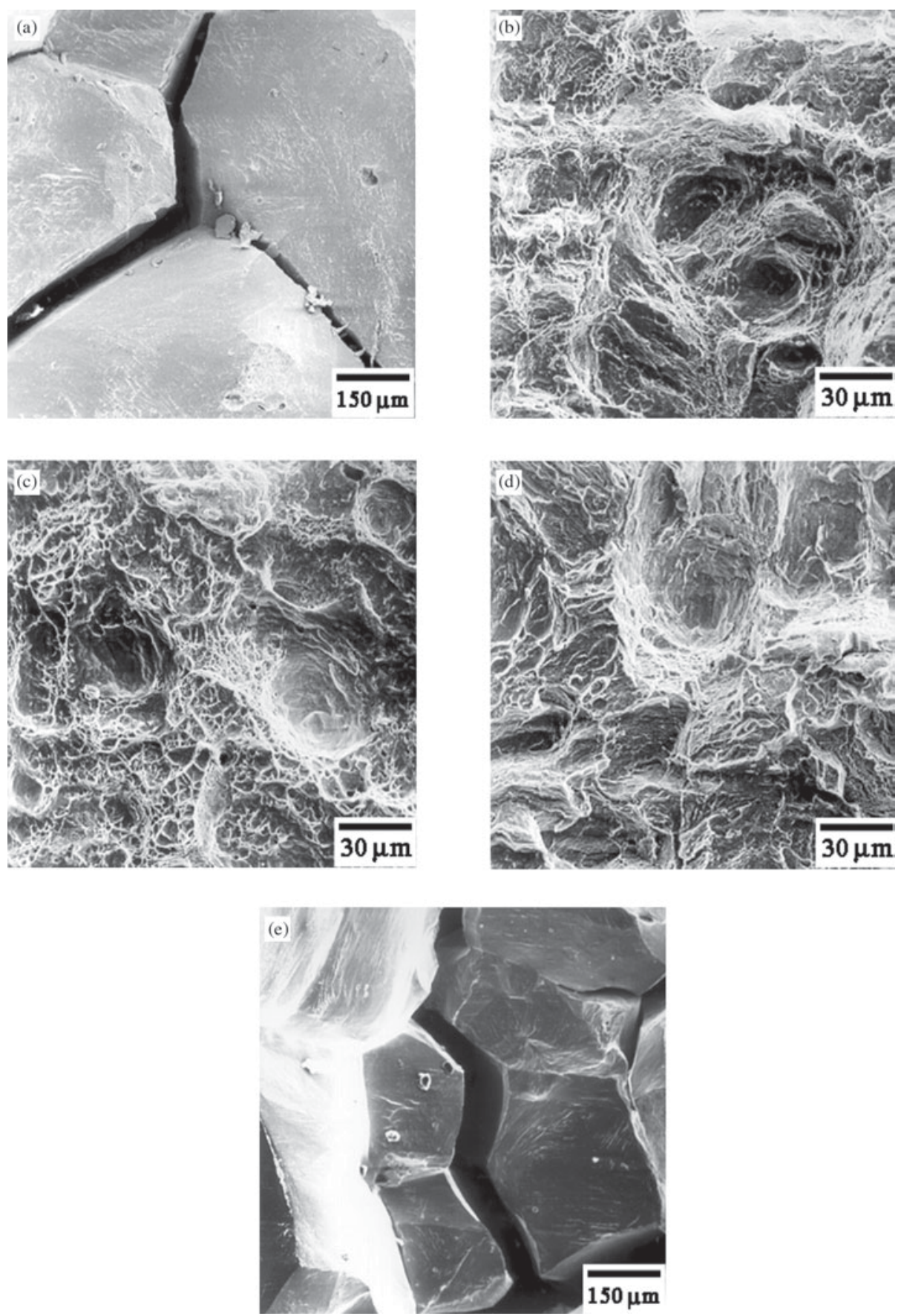

Figure 3. Fracture surface of specimens tested for J-R curves. A508-3A steel submitted to Q\&T thermal cycles: a) $\boldsymbol{I}$, b) $\boldsymbol{J}$, c) $\boldsymbol{K}$, d) $\boldsymbol{L}$ and e) $\boldsymbol{M}$. Crack growth direction is from the bottom to the top of the page.

for microalloyed steels, such as for microstructures $\boldsymbol{J}$ and $\boldsymbol{L}$, when higher loading rates inhibits ductility.

Figure $4 \mathrm{f}$ displays the fracture surface of the annealed microstructure $\boldsymbol{H}$, which exhibits a predominantly ductile aspect, which greatly differs from the honeycomb morphol- ogy presented earlier ${ }^{1}$, with shallow microvoids denoting a lower fracture toughness ${ }^{1}$. This indicates that the more severely annealed microstructures assessed in Part I, as well as the Q\&T, $\boldsymbol{I}, \boldsymbol{K}$ and $\boldsymbol{M}$, tend to show a reverse sensitivity to strain rate as above commented, i.e., increasing ductility 

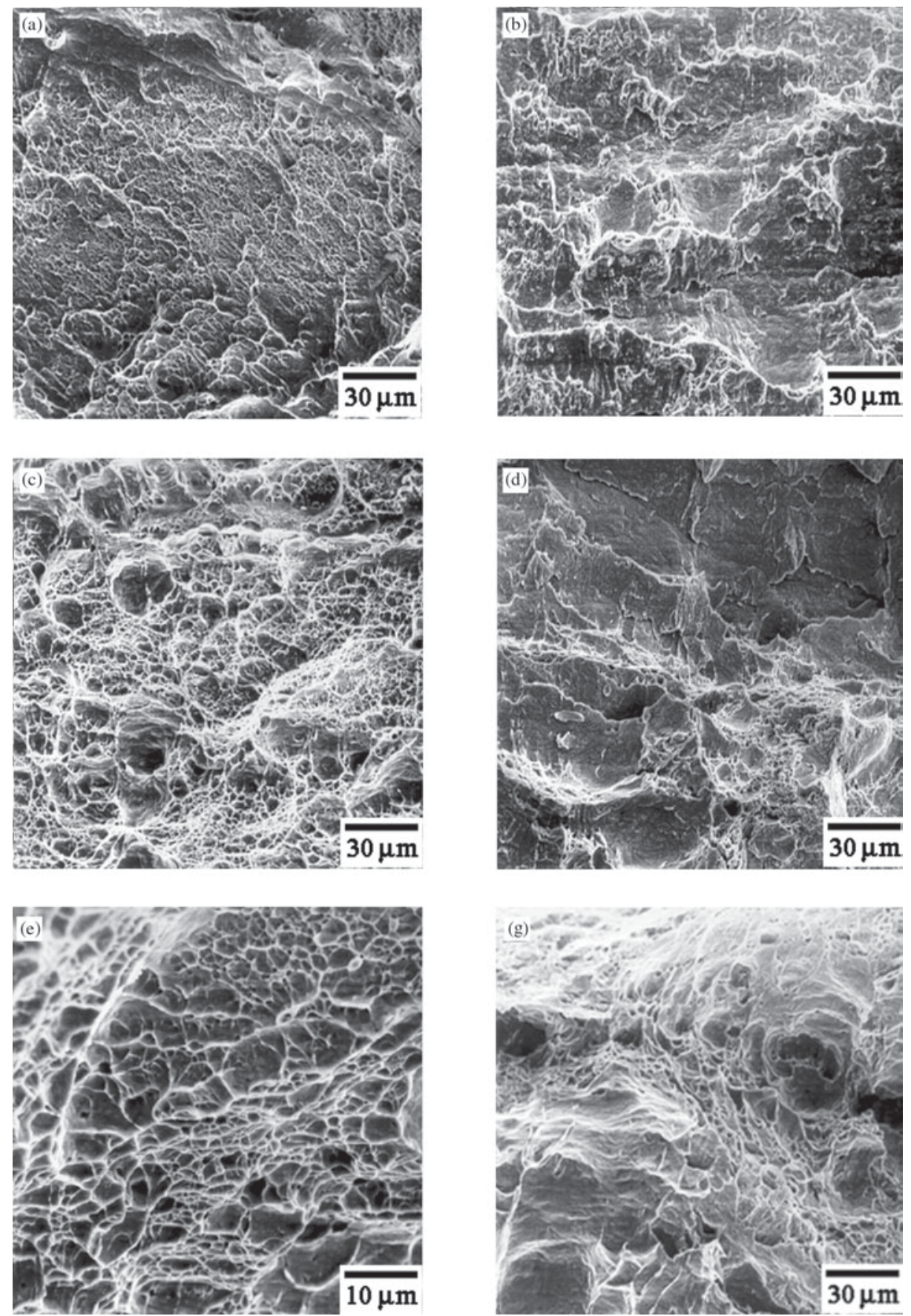

Figure 4. Fracture surfaces of impact Charpy specimens. A508 steel submitted to Q\&T thermal cycles a) $\boldsymbol{I}$, b) $\boldsymbol{J}$, c) $\boldsymbol{K}$, d) $\boldsymbol{L}$ and e) $\boldsymbol{M}$. f) annealed $\boldsymbol{H}$.

by raising the loading rate.

\section{Fracture Toughness Correlation}

Figure 5 plots the results obtained in fracture toughness tests under quasi-static and dynamic loading conditions for the original, $\boldsymbol{A}$, and Q\&T, $\boldsymbol{J}$ and $\boldsymbol{L}$, microstructures, which exhibited a fully elastic-plastic fracture behavior. The data referring to the microstructures $\boldsymbol{I}, \boldsymbol{K}$ e $\boldsymbol{M}$ have been omitted in this figure due to the occurrence of brittle fracture. A maximum correlation coefficient $(R)$ is observed for the linear relationship between the quasi-static $\left(\mathrm{dJ} / \mathrm{d} \Delta a_{(1 \mathrm{~mm})}{ }^{1}\right)$ and the impact Charpy energy, for three different J-R curve fit- 


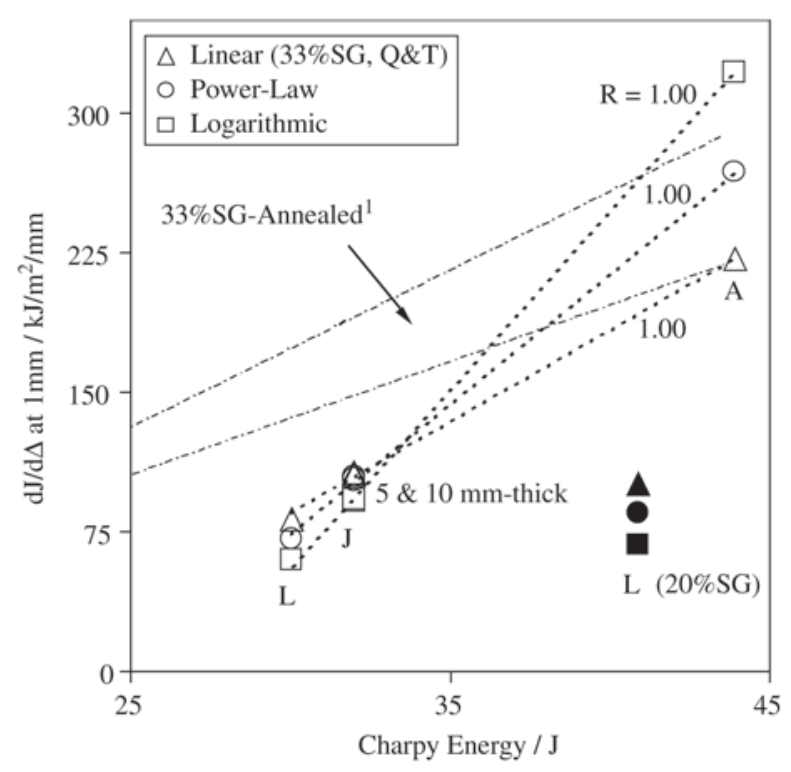

Figure 5. Correlation between quasi-static and dynamic fracture toughness parameters. J-R testpieces are $10 \mathrm{~mm}$-thick, otherwise stated. Charpy and J-R specimens are $33 \%$ side-grooved, otherwise indicated.

ting methods. The results obtained for the annealed microstructure $^{1}$ are provided for deals of comparison. These figures show that, for a fixed quasi-static fracture toughness level, the impact fracture toughness value is superior for Q\&T microstructures, as compared to the annealed materilas. This strengthens the previously mentioned tendency of induced-ductility by increasing the strain rate in Q\&T microstructures. Considering the grain size listed in Table I for microstructures $\boldsymbol{A}, \boldsymbol{J}$ and $\boldsymbol{L}$, and both quasi-static and dynamic fracture toughness values as well, it is possible to infer a Hall-Petch type relationship ${ }^{5,6}$ for those material conditions. Still in Fig. 5, the so-desired specimen size independence of the parameter $\mathrm{dJ} / \mathrm{d} \Delta a_{(1 \mathrm{~mm})}$ is confirmed for the microstructure $\boldsymbol{J}$. It should be emphasized that both the aforementioned facts agree quite well with results verified in Part I for annealed microstructures. Finally, J-R curve and Charpy impact test results are presented for $20 \%$ side grooved specimens made of microstructure $\boldsymbol{L}$; they illustrates the effect of the side-grooving level on the absorbed energy under quasi-static and impact loading circumstances.

\section{Concluding Remarks}

This study has shown the feasibility, although limited, of obtaining different elastic-plastic fracture toughness levels from quenching and tempering (Q\&T) a A508-3A steel, in order to simulate the mechanical behavior of neutron dose exposed reactor pressure vessel materials. However, similar to the annealed microstructures presented in Part I, and with the advantage in simulating more properly both the hardening and strengthening phenomena, the application of Q\&T heat treatments to structural alloy steels may lead to valuable implications related to cost, time and risk reductions concerned to pressurized water reactor vessels technology. Likewise annealed microstructures, it was also demonstrated the existence of a well defined linear relationship between fracture toughness values derived under quasi-static and dynamic loading regimes for Q\&T materials. As also realized for the annealed microstructures in Part I, a HallPetch type relationship was invoked to explain the effect of the bainite packet size on the elastic-plastic fracture toughnesses of the materials tested.

\section{Acknowledgements}

The authors gratefully acknowledge the financial support provided by FAPESP - Fundação de Amparo à Pesquisa do Estado de São Paulo (Contracts 97/05652-1 and 99/ 09431-5) and CNPq - Conselho Nacional de Pesquisa e Desenvolvimento (140789/2000-6).

\section{References}

1. Tarpani, J.R. et al. Part I, Mat. Res., v.5, v. 3, p. 357-364, 2002.

2. Bowen, P. et al. Acta Metall., v. 34, p. 1121-1131, 1986.

3. Bowen, P.; Knott, J.F. Metal Sci., v. 18, p. 225-235, 1984.

4. Bowen, P. et al. Acta Metall., v. 32, p. 637-647, 1984.

5. Petch, N.J J. Iron Steel Inst., v. 174, p. 25-32, 1953.

6. Hall, E.O. Proc. Phys. Soc. B., v. 64, p. 747-753, 1951. 